\title{
Facile Synthesis of Cobalt Phosphate Hydrate Nanosheets with Enhanced Nonenzymatic Glucose Sensing
}

\author{
Daojun Zhang ${ }^{*}$, Jiakai Li, Ruguang Li, Zimo Wang, Jingjing Wei, Xiaobei Zhang, Bei Jiang, Jingchao \\ Zhang, Renchun Zhang* \\ College of Chemistry and Chemical Engineering, Anyang Normal University, Anyang 455000, Henan, \\ China \\ *E-mail: zhangdj0410@ sohu.com, rczhang@aynu.edu.cn
}

doi: $10.20964 / 2019.12 .72$

Received: 1 June 2019 / Accepted: 20 September 2019 / Published: 29 October 2019

\begin{abstract}
In recent years, reports have shown that two-dimensional material's unique properties provide highly accessible surface areas and abundant active sites for contact with target analyser, electrolyte, and electron during catalytic processes. Herein, cobalt phosphate hydrate nanosheets were synthesised via a mild solvothermal method at $140{ }^{\circ} \mathrm{C}$ for $12 \mathrm{~h}$, which were adopted into nanosheet modified glass carbon electrode displaying excellent electrocatalytic performance toward glucose detection in basic electrolyte. Electrochemical analysis showed that cobalt phosphate hydrate based non-enzymatic sensor possesses excellent efficiency and stability, low detection limit, and high anti-interference performance.
\end{abstract}

Keywords: Nanosheets; Electrochemical sensor; Non-enzymatic glucose detection

\section{$\underline{\text { FULL TEXT }}$}

(C) 2019 The Authors. Published by ESG (www.electrochemsci.org). This article is an open access article distributed under the terms and conditions of the Creative Commons Attribution license (http://creativecommons.org/licenses/by/4.0/). 